\title{
Depression is a major determinant of sleep abnormalities in patients with epilepsy
}

\section{A depressão é um dos principais determinantes das anormalidades do sono em pacientes com epilepsia}

\author{
Edanur KARAPINAR', Ceren YUNUSOĞLU1', Betül TEKIN², Hava Özlem DEDE , Nerses BEBEK', \\ Betül BAYKAN ${ }^{1}$, Candan GÜRSES ${ }^{3}$
}

\begin{abstract}
Introduction: We aimed to identify sleep disorders in patients with epilepsy and compare this group with a healthy population. We also analyzed the features of sleep disorders in patients with epilepsy to demonstrate the effect of seizures and seizure types on sleep. Methods: Our study assessed 43 patients with epilepsy and 53 age- and gender-matched healthy controls. The demographic and clinical data of all participants were recorded. The Epworth Sleepiness Scale, Pittsburgh Sleep Quality Index (PSQI), International Restless Legs Syndrome Study Group Rating Scale, Berlin Questionnaire, and Beck Depression Inventory (BDI) were administered to all study subjects. The interview used to evaluate insomnia is based on the Diagnostic and Statistical Manual of Mental Disorders, $5^{\text {th }}$ Edition - DSM-5 diagnostic criteria. Results: Twenty-four patients (55.8\%) and 26 controls (49.1\%) are women. The mean age of patients and controls was $34.2 \pm 11.37$ (16$71)$ and $34.6 \pm 11.28$ (16-77), respectively. Patients with epilepsy had depression more often than controls, a result that was statistically significant $(p<0.0001)$. We found no statistically significant difference between sleep parameters of patients and controls with normal BDI scores ( $p>0.05)$. Patients with depression had worse results on the Berlin Questionnaire and PSQI total score, with statistical significance $(p=0.002)$. Nocturnal seizures, seizure type, and drug treatment had no effect on sleep ( $p>0.05)$. Conclusion: We concluded that depression rather than epilepsy negatively affects sleep, suggesting that all patients should be asked about their mood and sleep complaints.
\end{abstract}

Keywords: Epilepsy; Seizures; Depression; Sleep; Prognosis.

\begin{abstract}
RESUMO
Introdução: O objetivo deste estudo foi identificar distúrbios do sono em pacientes com epilepsia e compará-los com uma população saudável. Também foram examinadas as características dos distúrbios do sono em pacientes com epilepsia para demonstrar o efeito e os tipos de convulsões no sono. Métodos: 0 estudo consistiu em 43 pacientes com epilepsia e 53 controles saudáveis pareados por idade e sexo. Os dados demográficos e clínicos de todos os participantes foram registrados. Todos os participantes do estudo receberam a Escala de Sonolência de Epworth, o Índice de Qualidade do Sono de Pittsburgh (Pittsburch Sleep QUality Index — PSQI), o Questionário do Grupo Internacional de Estudos das Pernas Inquietas, o Questionário de Berlim e o Inventário de Depressão de Beck. A entrevista usada para avaliar a insônia é baseada nos critérios do DSM-V. Resultados: Vinte e quatro pacientes $(55,8 \%)$ são do sexo feminino e vinte e seis do

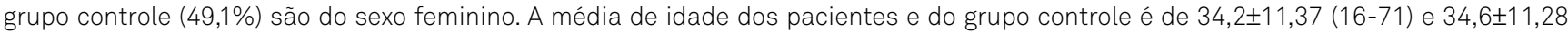
(16-77), respectivamente. Pacientes com epilepsia sofrem mais de depressão do que os controles e esse resultado é estatisticamente significativo $(p<0,0001)$. Não houve diferença estatisticamente significativa entre os parâmetros do sono dos pacientes e dos controles que apresentaram escores de Beck normais $(p>0,05)$. Pacientes com depressão apresentam resultados piores no escore total do PSQI de Berlim, o que é estatisticamente significativo $(p=0,002)$. As convulsões noturnas, o tipo de convulsão e o tratamento medicamentoso não afetaram o sono (p>0,05). Conclusão: Determinamos que a depressão, e não a epilepsia, afeta negativamente o sono dos pacientes, sugerindo que todos os pacientes devem ser questionados sobre seu humor e queixas de sono.
\end{abstract}

Palavras-chave: Epilepsia; Convulsões; Depressão; Sono; Prognóstico.

\footnotetext{
1Istanbul University, Istanbul School of Medicine, Department of Neurology, Fatih, İstanbul, Turkey.

2University of Health Sciences Prof. Dr. Mazhar Osman Bakırköy Research and Training Hospital for Psychiatry, Neurology, Neurosurgery, Department of Neurology, Bakırköy, Istanbul, Turkey.

${ }^{3}$ Koç University, Department of Neurology, Istanbul, Turkey.

Edanur KARAPINAR (D) https://orcid.org/0000-0002-58262041; Ceren YUNUSOĞLU (D) https://orcid.org/0000-0003-4112-6200;

Betül TEKIN (D) https://orcid.org/0000-0002-8946-6952; Hava Özlem DEDE (ID https://orcid.org/0000-0002-9900-2932;

Nerses BEBEK (D) https://orcid.org/0000-0002-4749-1471; Betül BAYKAN (DD https://orcid.org/0000-0002-3360-659X;

Candan GÜRSES (D) https://orcid.org/0000-0002-3752-1825

Correspondence: Betül Tekin; E-mail: betultekin2013@hotmail.com

Conflict of interest: There is no conflict of interest to declare.

Authors' contributions: EK, CY and HÖD: performed data collection. BT: data analysis and interpretation. EK: primary author. CG: conceived the ideas. CG BB and NB: provided revisions to scientific consent of manuscript. CG, BB and NB: principal investigators.
}

Received on September 19, 2019; Received in its final form on April 24, 2020; Accepted on May 27, 2020. 


\section{INTRODUCTION}

Epilepsy is a common neurological disease with a prevalence of $0.4-1 \%$. Sleep is an important aspect of life in patients with epilepsy, as they have a higher propensity for sleep disorders than the general population ${ }^{1}$. Epilepsy and sleep mutually affect each other. Both diurnal and nocturnal seizures deteriorate sleep structure ${ }^{1}$. Sleep apnea and sleep deprivation are among the most common sleep disorders that directly impact sleep quality and thereby trigger seizures ${ }^{2}$. Insomnia is one of the most frequent sleep disorders in patients with epilepsy, influencing their mood negatively ${ }^{3,4}$. Excessive daytime sleepiness, poor sleep quality, and restless legs syndrome are more common in patients with epilepsy and worsen their quality of life ${ }^{5}$. Mood disorders, particularly depression, are known to have a higher prevalence in patients with epilepsy than the general population, which also has a negative effect on sleep ${ }^{6,7,8}$.

We aimed to identify sleep disorders in patients with epilepsy and compare this group with a healthy population. We also analyzed the features of sleep disorders in patients with epilepsy to demonstrate the effect of nocturnal seizures and seizure types on sleep.

\section{METHODS}

Our study assessed 43 patients with epilepsy, treated at the Epilepsy Outpatient Clinic of Istanbul University, Istanbul School of Medicine, Department of Neurology. The patients were recruited consecutively and selected according to the following criteria: being over 18 years of age, literate, without intellectual disability. We excluded patients with epilepsy who had comorbid chronic diseases and were taking medications other than antiepileptic drugs (AEDs). We also included 53 age-matched healthy controls. Demographic characteristics of both patients and healthy controls were recorded, as well as the clinical features of the patients.

We administered the questionnaires and conducted an interview to determine the presence of sleep disorders and insomnia. The descriptions of our questionnaires are:

Epworth Sleepiness Scale (ESS): ESS is an eight-item questionnaire that evaluates daytime sleepiness. A total score equal to or greater than 10 indicates excessive daytime sleepiness ${ }^{9}$.

International Restless Legs Syndrome Study Group (IRLSSG) Rating Scale: The IRLSSG rating scale is considered the gold standard for evaluating restless legs syndrome (RLS) severity. This rating scale comprises 10 questions, with scores ranging from 0 to 4 . The score is classified as 1-10: mild; 11-20: moderate; 21-30: severe; 31-40: very severe ${ }^{10}$.

Pittsburgh Sleep Quality Index (PSQI): In PSQI, general sleep patterns are evaluated based on 18 questions distributed into 7 subscales: subjective sleep quality, sleep latency, sleep duration, sleep efficiency, sleep disturbances, use of sleep medication, and daytime dysfunction over the prior month. A total score of five or more indicates poor sleep quality ${ }^{11}$.

Berlin Questionnaire (BQ): BQ screens for obstructive sleep apnea (OSA) in the community and comprises 10 questions in 3 categories. Each category is evaluated individually, and if two or more categories have positive results, the OSA risk is considered high ${ }^{12}$.

Beck Depression Inventory (BDI) and Diagnostic and Statistical Manual of Mental Disorders, $5^{\text {th }}$ Edition - DSM-5 criteria: These criteria evaluate mood and depression, as well as insomnia ${ }^{13,14}$.

Test results of both groups were compared, followed by a study of the relationship between clinical findings of epilepsy (seizure type, presence of nocturnal seizures, seizure freedom, and treatment) and test results.

All participants were informed that this research analyzes the features of sleep disorders in patients with epilepsy and the healthy population. Informed written consent was obtained from all participants before they answered the questionnaires.

The study was approved by the Ethics Committee of Istanbul University, Istanbul School of Medicine (2015/1741).

\section{Statistical analysis}

Study data were analyzed using the Statistical Package for the Social Sciences (SPSS), version 21.0, and a $p<0.05$ was considered statistically significant. Continuous variables are expressed as meantstandard deviation (SD); categorical variables are presented as frequencies and percentages. The chi-square test, the Student's t-test, and the Neyman-Pearson likelihood ratio were used to determine the statistical significance of differences in means and proportions.

\section{RESULTS}

Our study included 43 patients with epilepsy and 53 healthy controls. Twenty-four patients $(55.8 \%)$ are women, and $19(44.2 \%)$ are men. Twenty-six controls $(49.1 \%)$ are women, and $27(50.9 \%)$ are men. The mean age of the patients was $34.2 \pm 11.37$ (16-71) and of the control group was $34.6 \pm 11.28$ (16-77). We found no significant difference between the two groups as to age, gender, and body mass index (BMI) $(p>0.05)$. The mean age at seizure onset was $19.2 \pm 14.93$ (1-69). Twenty-three (53.5\%) patients had focal seizures, and 20 (46.5\%) had generalized seizures (Table 1).

All patients were using AEDs - 22 (51.2\%) on monotherapy and $21(48.8 \%)$ on polytherapy. The most frequently used drugs were levetiracetam (11 patients - 11.5\%), carbamazepine (5 patients $-5.2 \%$ ), and lamotrigine 
(3 patients - 3.6\%). Mood disorders are very likely to affect sleep quality. The prevalence of depression was $37.2 \%$ (27 individuals) in the patient group and $16.9 \%$ (9 individuals) in the control group, which was statistically significant according to BDI $(\mathrm{p}<0.001)$ (Table 1$)$.

Table 1. Demographic and clinical features of patient and control groups.

\begin{tabular}{lccc}
\hline & $\mathrm{n}=43(\%)$ & Control=53 (\%) & $\mathrm{p}$-value \\
\hline Age (years) & $\begin{array}{c}34.2 \pm 11.37 \\
(16-71)\end{array}$ & $\begin{array}{c}34.6 \pm 11.28 \\
(16-77)\end{array}$ & 0.85 \\
\hline $\begin{array}{l}\text { Gender (Female/ } \\
\text { Male) }\end{array}$ & $\begin{array}{c}24(55.8) / 19 \\
(44.2)\end{array}$ & $\begin{array}{c}26(49.1) / 27 \\
(50.9)\end{array}$ & 0.51 \\
$\begin{array}{l}\text { Age onset of } \\
\text { seizures (year) }\end{array}$ & $\begin{array}{c}19.2 \pm 14.93 \\
\text { Duration of }\end{array}$ & - & \\
$\begin{array}{l}15.0 \pm 12.88 \\
(1-48)\end{array}$ & - & \\
disease (year) & & & \\
Epilepsy type & & & \\
Focal & $23(53.5)$ & & \\
Generalized & $20(46.5)$ & &
\end{tabular}

Seizure freedom (in the last year)

Yes $13(30.2)$

No $\quad 30(69.8)$

Seizure type

Focal $13(30.2)$

SGS $\quad 10(23.3)$

GS $\quad 20(46.5)$

\begin{tabular}{ll} 
Cranial MRI & \\
Normal & $21(48.8)$ \\
Abnormal & $22(51.2)$ \\
\hline EEG
\end{tabular}

\begin{tabular}{|c|c|c|c|}
\hline Normal & $9(20.9)$ & & \\
\hline $\begin{array}{l}\text { Generalized } \\
\text { abnormality }\end{array}$ & $19(44.2)$ & & \\
\hline $\begin{array}{l}\text { Focal } \\
\text { abnormality }\end{array}$ & $15(34.9)$ & - & \\
\hline \multicolumn{4}{|l|}{ AED } \\
\hline Monotherapy & $22(51.2)$ & & \\
\hline $\mathrm{CBZ}$ & 5 (11.6) & & \\
\hline VPA & $2(4.7)$ & & \\
\hline LEV & $11(26.6)$ & & \\
\hline LTG & $3(7)$ & & \\
\hline OXC & $1(2.3)$ & & \\
\hline Polytherapy & $21(48.8)$ & & \\
\hline BMI & $25 \pm 3.8$ & $24 \pm 3.7$ & 0.56 \\
\hline BDI scores & $14.9 \pm 10.9$ & $6.6 \pm 5.3$ & $<0.0001^{*}$ \\
\hline
\end{tabular}

${ }^{*}$ p $<0.05$; EEG: electroencephalogram; AED: antiepileptic drugs; CBZ: carbamazepine; VPA: valproate; LEV: levetiracetam; LTG: lamotrigine; oxcarbazepine; BDI: Beck Depression Inventory; BMI: body mass index; SGS: secondary generalized seizure; GS: generalized seizure. MRI: Magnetic resonance imaging.
In order to eliminate the negative impact of depression on sleep and focus only on the impact of epilepsy on sleep, we compared sleep parameters of patients and controls with normal BDI scores. No statistically significant difference was found between the groups ( $p>0.05$ ) (Table 2).

Epilepsy type, nocturnal seizures, monotherapy/polytherapy, and seizure freedom were not effective sleep parameters ( $p>0.05)$ (Table 3$)$.

Duration of disease and age at onset showed no significant correlation to test scores ( $p>0.05$ ) (Table 4).

We divided our patients with epilepsy according to BDI. Patients with high BDI scores had worse PSQI total score (Table 5).

\section{DISCUSSION}

Our main objective was to identify sleep disorders in patients with epilepsy. Our study showed that depression is more common in patients with epilepsy than in healthy controls, as also indicated previously ${ }^{15,16}$. The higher frequency of depression in patients with epilepsy can be explained as an effect of having a chronic disease ${ }^{17}$. On the other hand, depression has a negative effect on sleep ${ }^{5,18,19}$. We detected no difference between patients and healthy controls with normal BDI scores regarding sleep scores.

Insomnia is highly reported in patients with epilepsy ${ }^{20}$. Seizures, which cause sleep fragmentation and arousals, and/ or the effects of AEDs might justify this high prevalence ${ }^{21}$. Our study found no significant difference in terms of insomnia.

Table 2. Questionnaire scores of the patients and controls with normal Beck Depression Inventory scores.

\begin{tabular}{|c|c|c|c|}
\hline & Patients n:16 (\%) & Controls n: $44(\%)$ & $p$-value \\
\hline \multicolumn{4}{|l|}{ ESS } \\
\hline $0-9$ & $16(100)$ & $40(90.9)$ & \multirow{2}{*}{0.56} \\
\hline$>10$ & $0(0)$ & $4(9.1)$ & \\
\hline \multicolumn{4}{|c|}{ IRLSSG rating scale } \\
\hline 0 & $14(87.4)$ & 37 (84.1) & \multirow{3}{*}{0.93} \\
\hline $1-10$ & $1(6.3)$ & $4(9.1)$ & \\
\hline $11-20$ & $1(6.3)$ & $3(6.8)$ & \\
\hline \multicolumn{4}{|c|}{ Berlin Questionnaire } \\
\hline $0-1$ & $14(87.5)$ & $40(90.9)$ & \multirow{2}{*}{0.65} \\
\hline$>2$ & $2(12.5)$ & $4(9.1)$ & \\
\hline \multicolumn{4}{|l|}{ PSQI } \\
\hline $0-4$ & $13(81.2)$ & $34(77.3)$ & \multirow{2}{*}{0.74} \\
\hline$>5$ & $3(18.8)$ & $10(22.7)$ & \\
\hline $\begin{array}{l}\text { Insomnia } \\
(+/-)(\%)\end{array}$ & $2(12.5) / 14(87.5)$ & $1(2.3) / 43(97.7)$ & 0.17 \\
\hline
\end{tabular}

BDI: Beck Depression Inventory; ESS: Epworth Sleepiness Scale. IRLSSG: International Restless Legs Syndrome Study Group; PSQI: Pittsburgh Sleep Quality Index. 
Table 3. Sleep questionnaire results of patients with epilepsy and normal Beck Depression Inventory scores.

\begin{tabular}{|c|c|c|c|c|}
\hline$n=16$ & $\begin{array}{c}\text { Epilepsy type } \\
\begin{array}{c}\text { (Focal/Generalized) } \\
(\mathrm{n} / \%)\end{array}\end{array}$ & $\begin{array}{l}\text { Nocturnal seizure } \\
\text { (Yes/No) } \\
(\mathrm{n} / \%)\end{array}$ & $\begin{array}{c}\text { Treatment } \\
\begin{array}{c}\text { Monotherapy/Polytherapy } \\
(\mathrm{n} / \%)\end{array}\end{array}$ & $\begin{array}{l}\text { Seizure free } \\
\text { (Yes/No) } \\
(n / \%)\end{array}$ \\
\hline \multicolumn{5}{|l|}{ ESS } \\
\hline $0-9$ & $5(100) / 11(100)$ & $7(100) / 9(100)$ & $8(100) / 8(100)$ & $6(100) / 10(100)$ \\
\hline$>10$ & $0(0) / 0(0)$ & $0(0) / 0(0)$ & $0(0) / 0(0)$ & $0(0) / 0(0)$ \\
\hline \multicolumn{5}{|c|}{ IRLSSG rating scale } \\
\hline 0 & $5(100) / 9(81.8)$ & $6(85.7) / 8(88.9)$ & $7(7.5) / 7(87.5)$ & $6(100) / 8(80)$ \\
\hline $1-10$ & $0(0) / 1(9.1)$ & $0(0) / 1(11.1)$ & $0(0) / 1(12.5)$ & $0(0) / 1(10)$ \\
\hline $11-20$ & $0(0) / 1(9.1)$ & $1(14.3) / 0(0)$ & $1(12.5) / 0(0)$ & $0(0) / 1(10)$ \\
\hline \multicolumn{5}{|c|}{ Berlin Questionnaire } \\
\hline $0-1$ & $5(100) / 9(81.8)$ & $7(100) / 7(77.8)$ & $7(87.5) / 7$ (87.5) & $5(83.3) / 9(90)$ \\
\hline$>2$ & $0(0) / 2(18.2)$ & $0(0) / 2(22.2)$ & $1(12.5) / 1(12.5)$ & $1(16.7) / 1(0)$ \\
\hline \multicolumn{5}{|l|}{ PSQI } \\
\hline $0-4$ & $4(80) / 9(81.8)$ & $6(85.7) / 7(77.8)$ & $8(100) / 5(62.5)$ & $4(66.7) / 9(90)$ \\
\hline$>5$ & $1(20) / 2(18.2)$ & $1(14.3) / 2(22.2)$ & $0(0) / 3(37.5)$ & $2(33.3) / 1(10)$ \\
\hline Insomnia (+) (\%) & $0(0) / 2(18.2)$ & $1(11.1) / 1(14.3)$ & $1(12.5) / 1(12.5)$ & $1(10.0) / 1(16.7)$ \\
\hline
\end{tabular}

BDI: Beck Depression Inventory; ESS: Epworth Sleepiness Scale. IRLSSG: International Restless Legs Syndrome Study Group; PSQI: Pittsburgh Sleep Quality Index

Table 4. Sleep questionnaire results of patients with epilepsy and normal Beck Depression Inventory scores.

\begin{tabular}{lccccc}
\hline $\mathrm{n}=16$ & & ESS & PSQI & IRLSSG rating scale & Berlin Questionnaire \\
\hline \multirow{2}{*}{ Age at onset } & Pearson's correlation & 0.16 & -0.36 & -0.08 & 0.46 \\
\multirow{2}{*}{ Duration of disease } & p-value & 0.55 & 0.17 & 0.74 & 0.07 \\
& Pearson's correlation & 0.16 & -0.05 & 0.18 & 0.13 \\
\hline
\end{tabular}

BDI: Beck Depression Inventory; ESS: Epworth Sleepiness Scale; IRLSSG: International Restless Legs Syndrome Study Group; PSQI: Pittsburgh Sleep Quality Index; ${ }^{*} p<0.05$.

Table 5. Questionnaires of patients with normal and abnormal Beck Depression Inventory scores.

\begin{tabular}{|c|c|c|c|}
\hline$n=43$ & $\begin{array}{c}\text { Normal BDI } \\
\text { scores } n=16(\%)\end{array}$ & $\begin{array}{c}\text { Abnormal BDI } \\
\text { scores } n=27(\%)\end{array}$ & $\mathrm{p}$-value \\
\hline \multicolumn{4}{|l|}{ ESS } \\
\hline $0-9$ & $16(100)$ & $21(77.8)$ & \multirow{2}{*}{0.06} \\
\hline$>10$ & $0(0)$ & $6(22.2)$ & \\
\hline \multicolumn{4}{|c|}{ IRLSSG rating scale } \\
\hline 0 & $14(87.4)$ & $20(76.9)$ & \multirow{4}{*}{0.27} \\
\hline $1-10$ & $1(6.3)$ & $0(0)$ & \\
\hline $11-20$ & $1(6.3)$ & $3(11.5)$ & \\
\hline $21-30$ & 0 & $3(11.5)$ & \\
\hline \multicolumn{4}{|c|}{ Berlin Questionnaire } \\
\hline $0-1$ & $14(87.5)$ & $22(81.5)$ & \multirow{2}{*}{0.69} \\
\hline$>2$ & $2(12.5)$ & $5(18.5)$ & \\
\hline \multicolumn{4}{|l|}{ PSQI } \\
\hline $0-4$ & $13(81.3)$ & 8 (29.6) & \multirow{2}{*}{$0.002^{*}$} \\
\hline$>5$ & $3(18.7)$ & $19(70.4)$ & \\
\hline $\begin{array}{l}\text { Insomnia (+) } \\
(\%)\end{array}$ & $2(12.5)$ & $6(22.2)$ & 0.68 \\
\hline
\end{tabular}

BDI: Beck Depression Inventory; ESS: Epworth Sleepiness Scale. IRLSSG: International Restless Legs Syndrome Study Group; PSQI: Pittsburgh Sleep Quality Index; ${ }^{*} p<0.05$.
Sleep problems in patients with epilepsy might have several pathophysiological explanations. Firstly, seizures are known to have a worsening effect on sleep. Both diurnal and nocturnal seizures deteriorate sleep structure. In addition, nocturnal seizures decrease total sleep duration, sleep efficiency, and increase sleep fragmentation, latency, and awakening ${ }^{1,22}$. Postictal state, which is usually caused by nocturnal seizures, decreases sleep quality ${ }^{23}$.

We also analyzed the sleep features of patients with epilepsy and without depression according to BDI and found no significant difference as to age at onset, duration of disease, epilepsy type, nocturnal seizures, monotherapy/polytherapy, and seizure freedom. Contradictory arguments have been presented about the effects of epilepsy type on sleep. Some researchers state that patients with focal epilepsy have poorer sleep quality than those with generalized epilepsy, while others report no significant difference ${ }^{19,24}$. A similar controversy also exists about diurnal/nocturnal seizures, seizure frequency, or seizure freedom in the previous year. Nocturnal seizures are believed to affect sleep by causing arousals and excessive daytime sleepiness ${ }^{1,19,25,26}$.

The effect of AEDs on sleep has also been a controversial subject among neurologists. Some argue that AEDs worsen sleep problems, leading to especially excessive daytime 
sleepiness ${ }^{21,27}$. Conversely, many researchers declare that the number and type of AEDs do not have any significant effect on sleep ${ }^{1,23,28}$. A subject that contradictory should be clarified with further detailed studies. We found no statistically significant difference with respect to monotherapy and polytherapy among our patients.

To double-check our starting hypothesis, we compared the sleep scales of patients with normal and high BDI scores. We identified that patients with depression had worse PSQI scores (total score, subjective sleep quality, sleep latency, daytime dysfunction) than individuals without this condition, confirming that depression has a greater impact on sleep disorders.

Our study has a few limitations. First, the sample size is small. In addition, sleep disorders were evaluated according to tests rather than polysomnography.

Epilepsy is known to have negative effects on sleep. However, comorbid depression may lead to even poorer sleep quality. Therefore, all patients with epilepsy must be asked about their mood and sleep complaints in routine follow-up to ensure the effectiveness of treatment.

\section{References}

1. van Golde EG, Gutter T, de Weerd AW. Sleep disturbances in people with epilepsy; prevalence impact and treatment. Sleep Med Rev. 2011 Dec;15(6):357-68. https://doi.org/10.1016/j.smrv.2011.01.002

2. Manni R, Terzaghi M. Comorbidity between epilepsy and sleep disorders. Epilepsy Res. 2010 Aug;90(3):171-7. https://doi. org/10.1016/j.eplepsyres.2010.05.006

3. Quigg M, Gharai S, Ruland J, Schroeder C, Hodges M, Ingersoll KS, et al. Insomnia in epilepsy is associated with continuing seizures and worse quality of life. Epilepsy Res. 2016 May;122:91-6. https://doi. org/10.1016/j.eplepsyres.2016.02.014

4. Belanger L, Harvey AG, Fortier-Brochu E, Beaulieu-Bonneau E, Eidelman P, Talbot L, et al. Impact of comorbid anxiety and depressive disorders on treatment response to cognitive behavior therapy for insomnia. J Consult Clin Psychol. 2016 Aug;84(8):659-67. https://doi.org/10.1037/ccp0000084

5. Im HJ, Park SH, Baek SH, Chu MK, Yang KI, Kim WJ, et al. Associations of impaired sleep quality. insomnia. and sleepiness with epilepsy: a questionnaire-based case-control study. Epilepsy Behav. 2016 Apr;57(Pt A):55-9. https://doi.org/10.1016/j.yebeh.2016.01.022

6. Salpekar JA, Mishra G, Hauptman AJ. Key issues in addressing the comorbidity of depression and pediatric epilepsy. Epilepsy Behav. 2015 May;46:12-8. https://doi.org/10.1016/j.yebeh.2015.02.036

7. Yang KI, Grigg-Damberger M, Andrews N, O'Rourke C, Bena J, Foldvary-Schaefer N. Severity of self-reported insomnia in adults with epilepsy is related to comorbid medical disorders and depressive symptoms. Epilepsy Behav. 2016 Jul;60:27-32. https:// doi.org/10.1016/j.yebeh.2016.03.023

8. Moser D, Pablik E, Aull-Watschinger S, Pataraia E, Wöber C, Seidel S. Depressive symptoms predict the quality of sleep in patients with partial epilepsy - A combined retrospective and prospective study. Epilepsy Behav. 2015 Jun;47:104-10. https://doi.org/10.1016/j. yebeh.2015.04.021

9. Johns MW. Sleepiness in different situations measured by the Epworth Sleepiness Scale. Sleep. 1994 Dec;17(8):703-10. https://doi. org/10.1093/sleep/17.8.703

10. Allen RP, Picchietti D, Hening WA, Trenkwalder C, Walters AS, Montplaisi J, et al. Restless Legs Syndrome D. Epidemiology workshop at the National Institutes of H. International Restless Legs Syndrome Study G. Restless legs syndrome: diagnostic criteria special considerations and epidemiology. A report from the restless legs syndrome diagnosis and epidemiology workshop at the National Institutes of Health. Sleep Med. 2003 Mar;4(2):101-19. https://doi. org/10.1016/s1389-9457(03)00010-8

11. Buysse DJ, Reynolds CF. $3^{\text {rd }}$, Monk TH, Berman SR, Kupfer DJ. The Pittsburgh Sleep Quality Index: a new instrument for psychiatric practice and research. Psychiatry Res. 1989 May;28(2):193-213. https://doi.org/10.1016/0165-1781(89)90047-4
12. Netzer NC, Stoohs RA, Netzer CM, Clark K, Strohl KP. Using the Berlin Questionnaire to identify patients at risk for the sleep apnea syndrome. Ann Intern Med. 1999 Oct 5;131(7):485-91. https://doi. org/10.7326/0003-4819-131-7-199910050-00002

13. Beck AT, Steer RA, Ball R, Ranieri W. Comparison of Beck Depression Inventories - IA and -II in psychiatric outpatients. J Pers Assess. 1996 Dec;67(3):588-97. https://doi.org/10.1207/ s15327752jpa6703_13

14. American Psychiatric Association. Diagnostic and Statistical Manual of Mental Disorders. 5. ed. Washington, DC: APA; 2013.

15. Stefanello S, Marin-Leon L, Fernandes PT, Min LL, Botega NJ, et al. Suicidal thoughts in epilepsy: a community-based study in Brazil. Epilepsy Behav. 2010 Apr;17(4):483-8. https://doi.org/10.1016/j. yebeh.2009.12.029

16. Komolafe MA, Sunmonu TA, Ogunrin OA, Disu JO, Ezeala BA, Abubakar SA, et al. Sleep disturbances among patients with epilepsy in Nigeria. Ann Afr Med. 2015 Apr-Jun;14(2):103-8. https:// doi.org/10.4103/1596-3519.149880

17. DeJean D, Giacomini M, Vanstone M, Brundisini F. Patient experiences of depression and anxiety with chronic disease: a systematic review and qualitative meta-synthesis. Ont Health Technol Assess Ser. 2013 Sep;13(16):1-33.

18. van Mill JG, Hoogendijk WJ, Vogelzangs N, van Dyck R, Penninx BW. Insomnia and sleep duration in a large cohort of patients with major depressive disorder and anxiety disorders. J Clin Psychiatry. 2010 Mar;71(3):239-46. https://doi.org/10.4088/JCP.09m05218gry

19. Unterberger I, Gabelia D, Prieschl M, Chea K, Hofer M, Högl B, et al. Sleep disorders and circadian rhythm in epilepsy revisited: a prospective controlled study. Sleep Med. 2015 Feb;16(2):237-42. https://doi.org/10.1016/j.sleep.2014.09.021

20. Macêdo P, Oliveira PS, Foldvary-Schaefer N, Gomes MM. Insomnia in people with epilepsy: A review of insomnia prevalence. risk factors and associations with epilepsy-related factors. Epilepsy Res. 2017 Sep;135:158-67. https://doi.org/10.1016/j. eplepsyres.2017.05.014

21. Parrino L, Smerieri A, Spaggiari MC, Terzano MG. Cyclic alternating pattern (CAP) and epilepsy during sleep: how a physiological rhythm modulates a pathological event. Clin Neurophysiol. 2000 Sep;111(Suppl 2):S39-46. https://doi.org/10.1016/s13882457(00)00400-4

22. Scarlatelli-Lima AV, Sukys-Claudino L, Watanabe N, Guarnieri R, Walz R, Lina K. How do people with drug-resistant mesial temporal lobe epilepsy sleep? A clinical and video-EEG with EOG and submental EMG for sleep staging study. eNeurologicalSci. 2016 Sep;4:34-41. https://doi.org/10.1016/j.ensci.2016.06.002

23. Jain SV, Kothare SV. Sleep and epilepsy. Semin Pediatr Neurol. 2015 Jun;22(2):86-92. https://doi.org/10.1016/j.spen.2015.03.005 
24. Vaughn BV, Ali I. Sleep and epilepsy: opportunities for diagnosis and treatment. Neurol Clin. $2012 \mathrm{Nov} ; 30(4): 1249-74$. https://doi. org/10.1016/j.ncl.2012.08.006

25. Shen $Y$, Zhang M, Wang Y, Wang L, Xu X, Xiao G, et al. Subjective sleep disturbance in Chinese adults with epilepsy: associations with affective symptoms. Epilepsy Res. 2017 Sep;135:150-7. https://doi. org/10.1016/j.eplepsyres.2017.06.014

26. Ismayilova V, Demir AU, Tezer FI. Subjective sleep disturbance in epilepsy patients at an outpatient clinic: a questionnaire-based study on prevalence. Epilepsy Res. 2015 Sep;115:119-25. https://doi. org/10.1016/j.eplepsyres.2015.06.009
27. Nayak CS, Sinha S, Nagappa M, Kandavel T, Taly AB. Effect of carbamazepine on the sleep microstructure of temporal lobe epilepsy patients: a cyclic alternating pattern-based study. Sleep Med. 2016 Oct;27:80-5. https://doi.org/10.1016/j. sleep.2016.08.017

28. Saraswati N, Nayak C, Sinha S, Nagappa M, Thennarasu K, Taly AB. Comparing sleep profiles between patients with juvenile myoclonic epilepsy and symptomatic partial epilepsy: Sleep questionnairebased study. Epilepsy Behav. 2017 Jan;66:34-8. https://doi. org/10.1016/j.yebeh.2016.10.009 